\title{
Periodontal Route of Administration
}

National Cancer Institute

\section{Source}

National Cancer Institute. Periodontal Route of Administration. NCI Thesaurus. Code C38294.

Administration of a substance within the tissues surrounding a tooth or teeth. 